\title{
Physicochemical study of extractants for extraction of rare earth element
}

\author{
R. Giri and G. Nath ${ }^{*}$
}

\begin{abstract}
Background: In nuclear technology, the solvent extraction is an important step for recovery of rare earth materials, purification, radionuclide production, and preparation of nuclear reactor materials. Tributyl phosphate (TBP) and toluene are taken as extractant and diluent, respectively, for study of extraction efficiency for rare earth element like $\mathrm{CeO}_{2}$.

Methods: In the present paper, idea of ultrasonic sound theory is intensively applied to study the physicochemical property of extractants and diluent pair.

Results: The experimental value of ultrasonic velocity, measured density, molar volume, and viscosity are used for computation of acoustical parameters and their excess values. The variations of physical and acoustical parameter are discussed in terms of molecular interactions. The prepared samples are treated for extraction of $\mathrm{CeO}_{2}$ by separating the organo-aqueous phase. The recovery of this reactor material with the help of this ultrasonic technique has been explained in terms of nature and extent of intermolecular interactions present in the binary mixture.
\end{abstract}

Conclusions: The ultrasonic treatment for the recovery of this material provides an optimum value of the binary mixture for recovery of $\mathrm{CeO}_{2}$.

Keywords: Solvent extraction, Rare earth element (REE), TBP, Ultrasonic velocity, Acoustic parameter

\section{Background}

The reprocessing of spent nuclear fuels is one of the key processes in the nuclear fuel cycle. As the conventional method suffers from many drawbacks in reprocessing of nuclear fuel from the view point of cost and minimization of waste, the development of a new process involving cost-effectiveness coupled with minimizing waste amount is a great challenge for the next generation reprocessing. Liquid-liquid extraction was one of the most promising methods of separating REE's material. The repeated use of different organic solvents for this process results in severe corrosion to the equipment, and usage of lots of volatile organic solvents may lead to severe environmental pollution. The real picturisation of the role of extractant-diluent pair (EDP) is not still well defined in spite of work by many workers in this field (Laxmi et al. 2015; Thirumaran and Jayakumar 2009; Liu et al. 2016; Mahapatra et al. 2014; Mastumiya et al. 2014; Bhatanagar et al. 2010; Joshi et al. 2010; Patel and Parsania 2010; Palani and Kalavathy 2011; Sakthipandi et al. 2012; Srivastava et al. 2014; Aswar and

\footnotetext{
* Correspondence: ganesh_nath99@yahoo.co.in

Veer Surendra Sai University of Technology, Burla Sambalpur, Odisha 768018, India
}

Chudhary 2014; Giri and Nath 2015). Thus, an optimal concentration or range of concentration of extractants with particular diluents is a serious concern in the solvent extraction or purex process. Thus, the aim of the present investigation is to make an attempt to find an optimum concentration of EDP used for extraction process. The accurate concentration of EDP and their variation with different physical factors can be well studied by the propagation of ultrasonic wave in the concerned medium.

To understand the basic process with the help of some fundamental parameter with easier way, another method called ultrasonic irradiation is more effective and efficient in this regard. The high frequency and short wavelength of ultrasonic wave makes it possible to interact with the atoms and materials of the concerned medium without any destruction of the medium or individual property of component. Tributyl phosphate (TBP) has been extensively used as a solvent in nuclear industry for fuel reprocessing due to its excellent chemical resistance and physical properties which results in better separation than other solvents. The extracting power of TBP is mainly due to presence of phosphoryl group which form solvates with the metal ions. The diluentlike toluene improves the physical properties of TBP by 
lowering its density and viscosity for better phase separation. Hence, it is important to study various physical properties of TBP in presence of diluent. In applications of liquid-liquid extraction processes for recycling of used nuclear fuel, the aqueous phase co-exists with an organic extracting phase which consists of a mixture of an extracting agent and a diluent. Cerium is a member of the lanthanide series of metals and is the most abundant of the rare earth elements in the earth's crust. When present in compounds, cerium exists in both the trivalent $\left(\mathrm{Ce}^{3+}\right)$ and the tetravalent $\left(\mathrm{Ce}^{4+}\right)$ state. Cerium is found in nature along with other lanthanide elements in the minerals like alanite, bastnasite, monazite, cerite, and samarskite; however, only bastnasite and monazite are important sources commercially. Because of its unique stability in the tetravalent state, cerium can be separated out from the other rare earth elements through oxidation (forming $\mathrm{CeO}_{2}$ ) followed by variable solubility filtration.

\section{Methods}

\section{Materials and instruments}

High purity and analytical grade samples of TBP (AR > $98 \%)$, toluene (AR > $99 \%), \mathrm{HNO}_{3}(\mathrm{AR}>15.5 \mathrm{~mol} / \mathrm{L})$, and $\mathrm{CeO}_{2}(\mathrm{AR}>99 \%)$ procured from $\mathrm{CDH}$ chemicals were used as received. The binary mixture were prepared on percentage basis $(w / w)$ by mixing known mass of toluene in appropriate masses of TBP and measuring their masses with the help of a high-precision electronic balance of (WENSAR, PGB 100, with accuracy $\pm 0.001 \mathrm{~g}$ ). The densities of all mixture as well as pure liquid were measured by a specific gravity bottle calibrated with deionized double-distilled water of density $0.9960 \times 10^{3} \mathrm{~kg} / \mathrm{m}^{3}$ at $303.15 \mathrm{~K}$. The precision of density measurement was within $\pm 0.0001 \mathrm{~kg} / \mathrm{m}^{3}$. The ultrasonic velocity in the mixtures as well as in the component liquids were measured at $303.15 \mathrm{~K}$ (calibrated up to $\pm 0.01 \mathrm{~m} / \mathrm{s}$ ) by a single-crystal variable-path multifrequency ultrasonic interferometer operating at different frequencies 1-4 MHz (Mittal Enterprises, New Delhi, Model-M-81S). The temperature of the mixture was maintained constant within $\pm 0.01 \mathrm{~K}$ by circulation of water from thermostatically regulated constant temperature water bath (B-206) through the waterjacketed cell. Viscosities of the mixtures were measured by Redwood apparatus (MAC, \#RWV-5271 was precise up to $\pm 0.0001 \mathrm{Nsm}^{-2}$ ).

\section{Experimental procedure}

Different concentrations of extractant were prepared by dissolving various amounts of TBP in toluene. All samples were stored in ground-glass stopper bottles to prevent the evaporation. The concentrations of extractant were studied and optimized by ultrasonic method in terms of existence of different intermolecular interaction explaining the various acoustic parameters with their deviated values. The ultrasonic velocity of the pure liquids and their freshly prepared mixtures of (TBP-toluene) were measured using multifrequency ultrasonic interferometer operating at different frequencies (1-4 MHz). The working principle used in the measurement of velocity of sound through medium was based on the accurate determination of the wavelength of ultrasonic waves of known frequency produced by quartz crystal in the measuring cell. The temperature of the solution was controlled by circulating water at a desired temperature through the jacket of a double-walled cell.

For extraction, equal volumes of two phases, organic and aqueous phases, were equilibrated in a separatory funnel by using magnetic stirrer at $200 \mathrm{rpm}$ for $10 \mathrm{~min}$ as shown in Fig. 1. Organic phase was equilibrated by adding TBP with toluene of different mole fractions, and aqueous phase was created by adding cerium oxide in diluted nitric acid using $25-\mathrm{mL}$ flask. After this, the necessary volumes of both aqueous and organic phases were put into a separatory funnel, which was dipped in ultrasonic bath for phase settle. After the phase settle, the extract was filtered through a $0.45-\mu$ m nylon membrane (Guangfu Chemical Reagents Co., Tianjin, China) prior to the analysis. Mass balance analysis was performed to verify the measured distribution ratios by comparing the theory of chemical equilibrium as per Nernst distribution law:

$$
K_{D}=\frac{[X]_{\text {org }}}{[X]_{\text {aqu }}}
$$

where the brackets denote the concentration of " $\mathrm{X}$ " in each phase at constant temperature (or the activity of " $\mathrm{X}$ " for nonideal solutions). By convention, the concentration extracted into organic and aqueous phase appears in the numerator and denominator of equation and the resulting value of $K_{D}$ is large, indicating a high degree of extraction from aqueous phase into organic phase. Conversely, if $K_{D}$ is small, less chemical $X$ is transferred from aqueous phase into organic phase. If $K_{D}$ is equal to 1 , equivalent concentrations exist in each phase.

\section{Theory}

The propagation of sound wave through a medium is due to the vibrations or oscillatory motions of particles within a medium (Fig. 2). An ultrasonic wave may be visualized as an infinite number of oscillating masses or particles connected by means of elastic springs. Each individual particle is influenced by the motion of its nearest neighbor and both inertial and elastic restoring forces act upon each particle. 

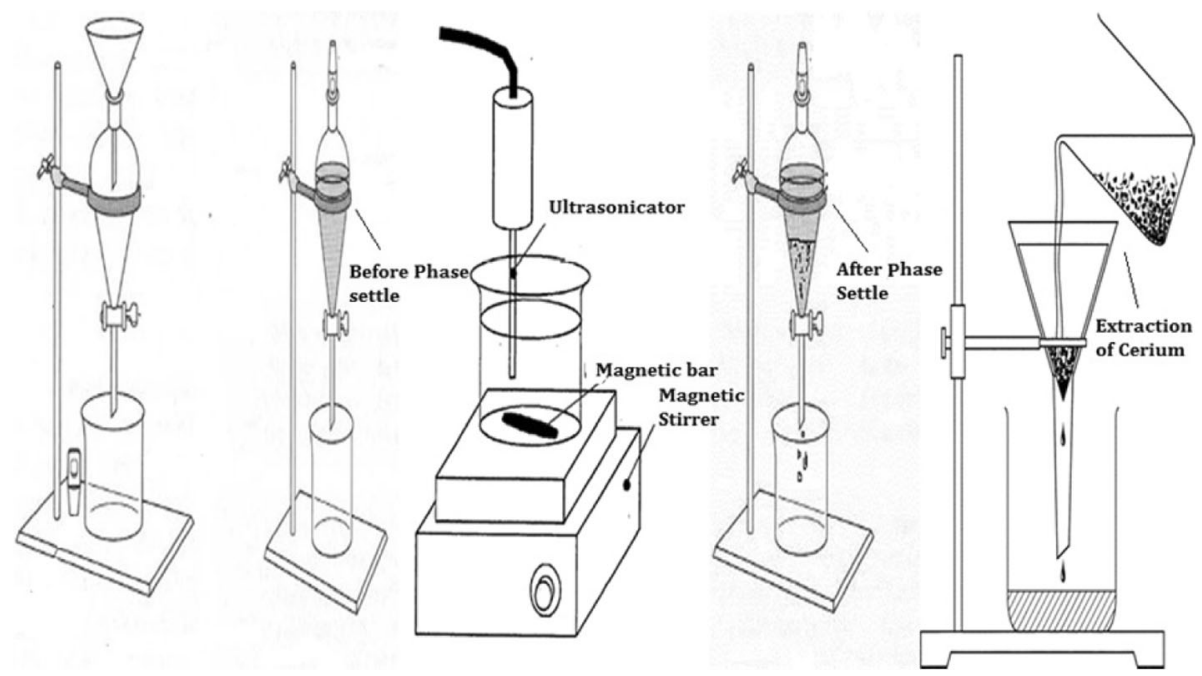

Fig. 1 Schematic diagram for extraction procedure of $\mathrm{Ce}$ form $\mathrm{CeO}_{2}$

Thus, the force acting on the atoms of the medium as per Hook's law is given as

$$
\begin{aligned}
& F \alpha-x \\
& F=-K x
\end{aligned}
$$

where $K$ is a constant depending on the nature of the medium on which the wave propagates and the intermolecular interaction. As the liquid medium is elastic, the wave equation is given by

$$
\frac{\partial^{2} \psi}{\partial x^{2}}=\frac{1}{C^{2}} \frac{\partial^{2} \psi}{\partial t^{2}}
$$

where " $C$ " is the velocity of the wave or ultrasonic wave propagating though the medium. The experimental measured values of ultrasonic velocity, density, and viscosity

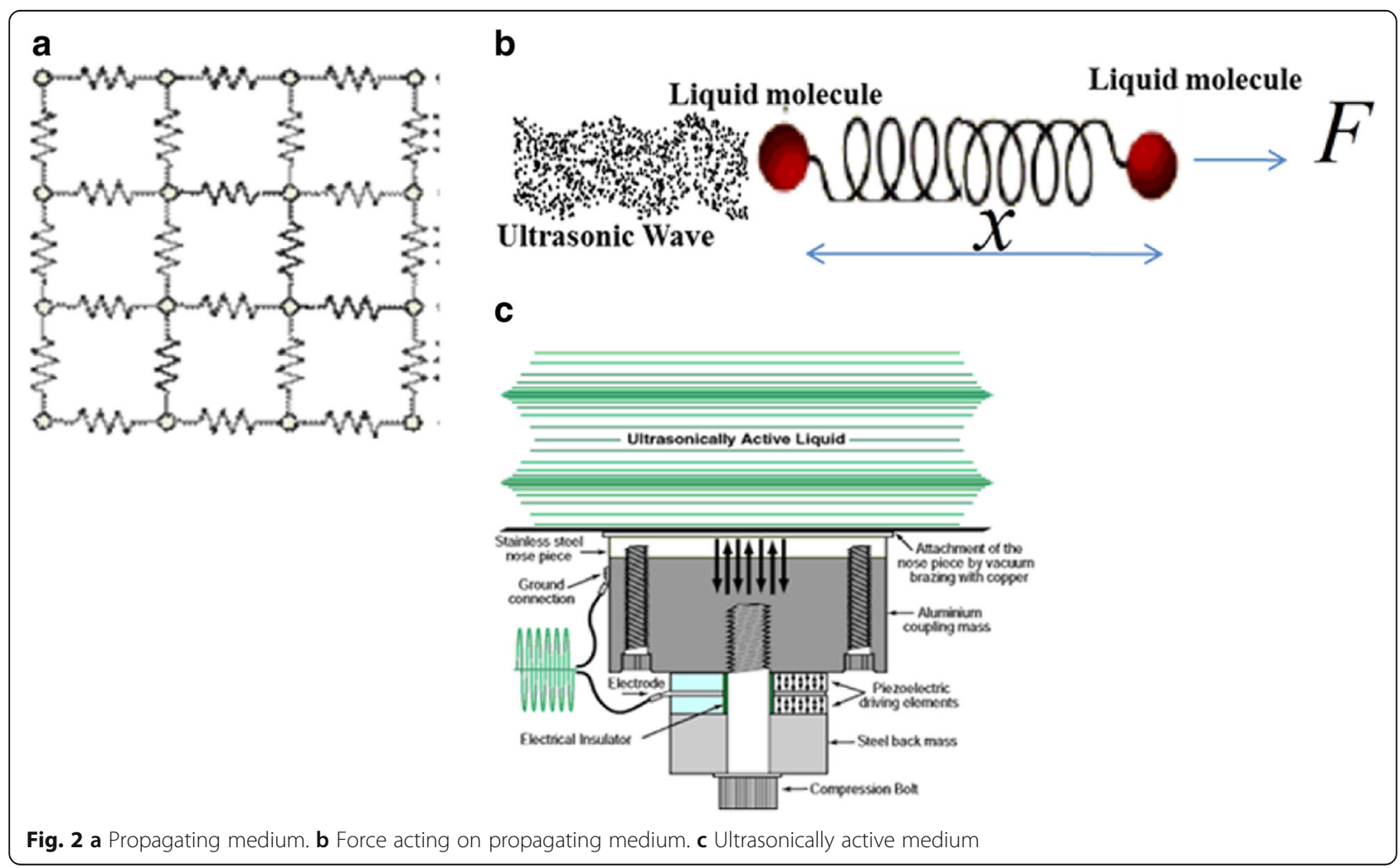


are used to compute different acoustic parameters such as isentropic compressibility $\left(\beta_{S}\right)$, intermolecular free length $\left(L_{f}\right)$, acoustic impedance $(Z)$, molar volume, and surface tension and their excess values which are well describing the physicochemical properties of the medium. The acoustic parameters have been evaluated with the help of the following relationship ( $\mathrm{Pal}$ and kumar 2011; Ali et al. 2004; Pradhan et al. 2012; Nadh et al. 2013).

$$
\begin{aligned}
& \text { Isentropic compressibility : } \beta_{S}=\frac{1}{\rho C^{2}} \\
& \text { Intermolecular free length : } L_{f}=k \beta^{1 / 2} \\
& \text { Acoustic impedance : } Z=\rho C \\
& \text { Molar volume : } V_{m}=\frac{M}{\rho} \\
& \text { Surface tension }: \sigma=6.4 \times 10^{-3} \rho C^{\frac{3}{2}}
\end{aligned}
$$

and their excess values are calculated as

$$
\left(Y^{E}\right)=Y_{\text {mix }}-\left(X_{A} Y_{A}+X_{B} Y_{B}\right)
$$

where $X_{A}$ and $X_{B}$ are the mole fractions, $Y_{A}, Y_{B}$, and $Y_{\text {mix }}$ represent the isentropic compressibility, intermolecular free length, acoustic impedance, molar volume, and surface tension of toluene, TBP, and mixture, respectively. The constant $k$ is temperature dependent which is given as $[93.875+(0.375 T)] \times 10^{-8}$ (Ali et al. 1996; Dey et al. 2015), $T$ being the absolute temperature.

\section{Results and discussion}

The density $(\rho)$ and viscosity $(\eta)$ values of pure liquids are reported in Table 1 (Liu et al. 2016; Gangwar et al. 2013; Moumouzias and Ritzoulis 1992). Experimental values of density $(\rho)$ and viscosity $(\eta)$ have been reported in Table 2 . The values of ultrasonic velocity $(C)$ and computed values of excess acoustic impedance $\left(Z^{E}\right)$, deviated values of isentropic compressibility $\left(\Delta \beta_{s}\right)$, excess intermolecular free length $\left(L_{f}^{E}\right)$, excess surface tension $\left(\sigma^{E}\right)$, excess molar volume $\left(V_{m}^{E}\right)$, and excess viscosity $\left(\eta^{E}\right)$ at temperature $303 \mathrm{~K}$ are presented in Tables 3 and 4, respectively. The distribution coefficient or percentage

Table 1 Experimental density $(\rho)$ and viscosity $(\eta)$ values for pure liquids with literature values

\begin{tabular}{llllll}
\hline Component & $\rho\left(\mathrm{Kgm}^{-3}\right)$ & & \multicolumn{2}{c}{$\eta\left(\mathrm{Nsm}^{-2}\right) \times 10^{-3}$} \\
\cline { 2 - 3 } & Expt. & Lit. & & Expt. & Lit. $^{\mathrm{a}}$ \\
\hline Tributyl phosphate & 950.578 & $974.800^{\mathrm{a}}$ & & 1.7818 & $1.0092^{\mathrm{a}}$ \\
Toluene & 854.456 & $834.800^{\mathrm{b}}$ & & 1.5862 & $1.0869^{\mathrm{c}}$ \\
\hline
\end{tabular}

${ }^{a}$ Ref. (Ali and Nain 1996) at $303.15 \mathrm{~K}$

${ }^{b}$ Ref. (Habashi 1993) at $308 \mathrm{~K}$

${ }^{\mathrm{C}}$ Ref. (Joshi et al. 2010) at $288.15 \mathrm{~K}$
Table 2 Experimental values of density $(\rho)$,viscosity $(\eta)$, and molar volume at temperature $303.15 \mathrm{~K}$

\begin{tabular}{lll}
\hline Mole fraction of TBP & Density $\left(\mathrm{Kgm}^{-3}\right)$ & Viscosity $\left(\mathrm{Nsm}^{-2}\right) \times 10^{-3}$ \\
\hline 0.0000 & 854.456 & 1.586227 \\
0.0712 & 869.182 & 1.571293 \\
0.1692 & 885.827 & 1.547224 \\
0.257 & 898.025 & 1.538582 \\
0.4356 & 916.129 & 1.572145 \\
0.5052 & 922.023 & 1.684754 \\
0.582 & 927.896 & 1.712247 \\
0.7059 & 935.953 & 1.734918 \\
0.7781 & 940.066 & 1.746461 \\
0.8712 & 945.001 & 1.764821 \\
1.0000 & 950.578 & 1.78184 \\
\hline
\end{tabular}

of extraction for each concentration of EDP has been reported in Table 5. A close perusal of the data for density and viscosity presented in Table 2 indicates that with increase of concentration of TBP, density of the solvent mixture increases linearly.

Density is a measure of solvent-solvent and solutesolvent interaction. For the system of TBP and toluene under study, there is an increase in density at lowconcentration region for nonpolar solvents like toluene (Fig. 3). Increase in density with concentration is due to the shrinkage in the volume of the mixture. In other words, the increase in density may be interpreted to the structure-maker of the solvent due to the added polar solvent. In the case of TBP/toluene mixture, there is a continuous increase in the density of the solution with an increase in concentration of TBP. This is attributed to the presence of strong intermolecular attraction such as dipole-dipole and dipole-induced dipole interaction (Ali et al. 1996; Ali and Nain 1996). Again, an increase in concentration of TBP allows for a closer approach of TBP molecules. As the polarity of the solvent increases, there is increase in density. The initial sharp increase in density can be explained on the basis of a sudden decrease in the volume of the solution with the addition of TBP.

Viscosity is the ease with which the solution flows. The viscosity values are seen to follow a decreasing trend with the increase in the mole fraction of TBP in up to mole fraction 0.4 and then exhibit a steady increase with increase in concentration of TBP (Fig. 4). This kind of behavior may be due to some agglomeration of complex formation occurring in the earlier stages, thereby causing a rise in the viscosity, which subsequently diminishes with increasing TBP concentration. As the viscosity of TBP is greater than that of toluene, its presence affects the viscosity of the mixture. The weak hydrogen bonding between the phosphorous- 
Table 3 Ultrasonic velocity $(C)$,excess acoustic impedance $\left(Z^{E}\right)$, excess isentropic compressibility $\left(\Delta \beta_{s}\right)$ of pure tributyl phosphate (TBP), toluene, and binary mixture of TBP and toluene at different mole fraction with different frequencies $(1-4 \mathrm{MHz})$ for temperature $303.15 \mathrm{~K}$

\begin{tabular}{|c|c|c|c|c|c|c|c|c|c|c|c|c|}
\hline \multirow{2}{*}{$\begin{array}{l}\text { Mole fraction of TBP } \\
\text { X1 }\end{array}$} & \multicolumn{4}{|l|}{$C(\mathrm{~m} / \mathrm{s})$} & \multicolumn{4}{|l|}{$Z^{\mathrm{E}}\left(\mathrm{Kgm}^{-2} \mathrm{~s}\right)$} & \multicolumn{4}{|l|}{$\Delta \beta_{s}\left(N^{-1} m^{-2}\right)$} \\
\hline & $1 \mathrm{MHz}$ & $2 \mathrm{MHz}$ & $3 \mathrm{MHz}$ & $4 \mathrm{MHz}$ & $1 \mathrm{MHz}$ & $2 \mathrm{MHz}$ & $3 \mathrm{MHz}$ & $4 \mathrm{MHz}$ & $1 \mathrm{MHz}$ & $2 \mathrm{MHz}$ & $3 \mathrm{MHz}$ & $4 \mathrm{MHz}$ \\
\hline 0.0000 & 1277 & 1276 & 1275 & 1274 & 0 & 0 & 0 & 0 & 0 & 0 & 0 & 0 \\
\hline 0.0712 & 1273 & 1272 & 1269 & 1266 & 8822.209136 & 9017.370483 & 7338.805523 & 5727.921717 & -24.0977223 & -23.5064086 & -29.1325544 & -34.5556821 \\
\hline 0.1692 & 1270 & 1267 & 1264 & 1263 & $18,398.69858$ & $17,094.45081$ & $15,468.52745$ & $15,775.09589$ & -40.2538249 & -44.5948991 & -49.8040229 & -48.8577351 \\
\hline 0.2570 & 1266 & 1263 & 1262 & 1260 & $22,275.00696$ & $21,192.98695$ & $21,418.41985$ & $20,990.12630$ & -51.6533634 & -55.1956038 & -54.4491710 & -55.8436206 \\
\hline 0.4356 & 1263 & 1260 & 1257 & 1254 & $26,126.04457$ & $25,516.19964$ & $24,078.21116$ & $23,054.29446$ & -45.1060738 & -47.1285120 & -51.4146950 & -54.5538893 \\
\hline 0.5052 & 1260 & 1257 & 1254 & 1252 & $24,444.13866$ & $24,021.78251$ & $22,638.96235$ & $22,658.39719$ & -44.9226509 & -46.3532079 & -50.4121021 & -50.4289483 \\
\hline 0.5820 & 1257 & 1254 & 1251 & 1248 & $22,042.54496$ & $21,828.96515$ & $20,508.91255$ & $19,742.09635$ & -42.4159704 & -43.2020031 & -47.0186650 & -49.3089136 \\
\hline 0.7059 & 1254 & 1250 & 1247 & 1244 & $18,040.51155$ & $17,232.04710$ & $16,017.50963$ & $15,473.98517$ & -30.3684272 & -32.8126061 & -36.2578405 & -37.8555057 \\
\hline 0.7781 & 1252 & 1248 & 1245 & 1242 & $14,720.53797$ & $14,108.45672$ & $12,957.15199$ & $12,545.49200$ & -22.7984274 & -24.6398124 & -27.8763920 & -29.0782435 \\
\hline 0.8712 & 1247 & 1244 & 1241 & 1238 & $7666.794,136$ & $8254.419,283$ & $7185.757,323$ & $6945.238,917$ & $-18.6133,625$ & -17.0301590 & $-19.9923,546$ & $-20.6784,768$ \\
\hline 1.0000 & 1244 & 1240 & 1238 & 1235 & 0 & 0 & 0 & 0 & 0 & 0 & 0 & 0 \\
\hline
\end{tabular}


Table 4 Excess intermolecular free length $\left(L_{f}^{E}\right)$, excess surface tension $\left(\sigma^{E}\right)$, excess molar volume $\left(V_{m}^{E}\right)$ and excess of pure tributyl phosphate (TBP), toluene, and binary mixture of TBP and toluene at different mole fractions with different frequencies (1-4 MHz) for temperature $303.15 \mathrm{~K}$

\begin{tabular}{|c|c|c|c|c|c|c|c|c|c|c|}
\hline \multirow{2}{*}{$\begin{array}{l}\text { Mole fraction } \\
\text { of TBP } \\
X_{1}\end{array}$} & \multicolumn{4}{|c|}{$\mathrm{Lf}_{f}^{\mathrm{E}}(\mathrm{m}) \times 10^{-7}$} & \multicolumn{4}{|l|}{$\sigma^{\mathrm{E}}\left(\mathrm{Nm}^{-1}\right)$} & \multirow[t]{2}{*}{$V_{m}^{E}\left(m^{3} \mathrm{~mol}^{-1}\right) \times 10^{-7}$} & \multirow[t]{2}{*}{$\eta^{E}\left(\mathrm{Nsm}^{-2}\right) \times 10^{-3}$} \\
\hline & $1 \mathrm{MHz}$ & $2 \mathrm{MHz}$ & $3 \mathrm{MHz}$ & $4 \mathrm{MHz}$ & $1 \mathrm{MHZ}$ & $2 \mathrm{MHz}$ & $3 \mathrm{MHz}$ & $4 \mathrm{MHz}$ & & \\
\hline 0.0000 & 0 & 0 & 0 & 0 & 0 & 0 & 0 & 0 & 0 & 0 \\
\hline 0.0712 & -5.5956 & -5.4484 & -6.8047 & -8.1131 & 1917.2819 & 1914.73468 & 1317.45752 & 721.1185634 & 1.71085 & -0.19532 \\
\hline 0.1692 & -9.3571 & -0.1040 & -0.1167 & -0.1144 & 4205.7083 & 3594.97437 & 2985.18984 & 2980.563116 & 2.92216 & -1.01283 \\
\hline 0.2570 & -0.1207 & -0.1293 & -0.1275 & -0.1309 & 5041.4163 & 4422.12243 & 4416.07006 & 4103.943175 & 3.26293 & -1.40152 \\
\hline 0.4356 & -0.1047 & -0.1095 & -0.1202 & -0.1280 & 6332.9984 & 5701.36007 & 5070.70978 & 4441.054575 & 4.91720 & -1.56675 \\
\hline 0.5052 & -0.1047 & -0.1081 & -0.1182 & -0.1182 & 5918.0402 & 5283.47561 & 4649.90730 & 4330.474264 & 4.73284 & -1.40087 \\
\hline 0.5820 & -9.9252 & -0.1010 & -0.1106 & -0.1164 & 5365.6501 & 4728.40132 & 4092.15698 & 3456.922601 & 4.18167 & -1.29212 \\
\hline 0.7059 & -7.0718 & -7.6757 & -8.5515 & -8.9522 & 4634.7341 & 3676.19462 & 3036.78807 & 2398.401336 & 3.28712 & -1.13512 \\
\hline 0.7781 & -5.2872 & -5.7421 & -6.5675 & -6.8693 & 3956.2692 & 2995.21656 & 2354.44540 & 1714.698945 & 2.58474 & -1.01863 \\
\hline 0.8712 & -4.4291 & -4.0174 & -4.7783 & -4.9529 & 2193.7445 & 1551.11883 & 909.521706 & 268.9558308 & 1.09628 & -0.28534 \\
\hline 1.0000 & 0 & 0 & 0 & 0 & 0 & 0 & 0 & 0 & 0 & 0 \\
\hline
\end{tabular}

oxygen $(\mathrm{P}=\mathrm{O})$ oxygen of $\mathrm{TBP}$ and the methyl group of toluene increase the resistance to flow, and thus, the viscosity increases (Tuck 1961).

The ultrasonic velocity decreases linearly with increasing concentration of TBP which is governed by the effect of density. The main cause of such variation is due to fact that there is large difference in density of toluene and TBP. The mixing of nonpolar solvent with polar solvent causes the energy change due to dipole-dipole interaction between the polar head groups of TBP molecules (Shieh and Fendler 1977; Goldman and Care 1971). Further, with increase of frequency, the ultrasonic velocity decreases. This may be attributed to the fact that, due to high oscillation of the solvent molecules causing the dispersion of energy (Nath et al. 2009a, 2009b; Nath and Paikaray 2009), TBP contains $\mathrm{P}=\mathrm{O}$ functional group which is polar, and hence, it can

Table 5 Percent extraction of cerium from $\mathrm{CeO}_{2}$ with concentration of extractant diluent pair

\begin{tabular}{ll}
\hline Mole fraction of EDP & \% extraction of cerium \\
\hline 0.0000 & 15 \\
0.0712 & 33 \\
0.1692 & 69 \\
0.257 & 75 \\
0.4356 & 88 \\
0.5052 & 87 \\
0.582 & 84 \\
0.7059 & 81 \\
0.7781 & 79 \\
0.8712 & 80 \\
1.0000 & 82 \\
\hline
\end{tabular}

interact with nonpolar molecules like toluene through polar-induced dipolar interaction. In pure TBP, there is dipole-dipole as well as the dispersive interaction. The effect of adding nonpolar second component is primarily to disrupt the dipolar interaction of the first component. For polar solvents, there is a decrease in velocity by increasing the concentration due to strong intermolecular interactions (Fig. 5).

The deviation in the physical property from its ideal behavior is a measure of the degree of interaction between component molecules of the solvent mixture (Pradhan et al. 2012). The variation in excess viscosity gives a quantitative estimation of the strength of intermolecular interactions, and these values can be explained by considering two factors. One is the difference in size and shape of the component molecules and the loss of dipolar association in pure compound that may lead to a decrease in viscosity.

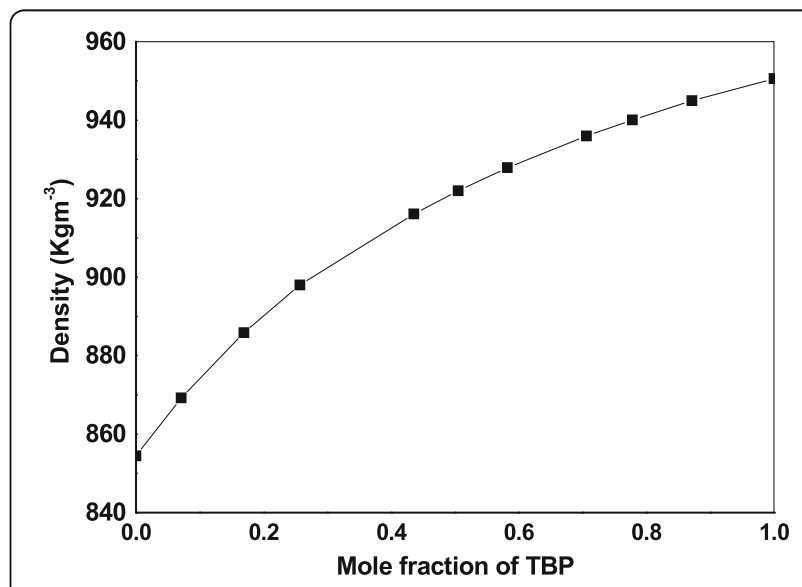

Fig. 3 Variation of density with different mole fractions of TBP 


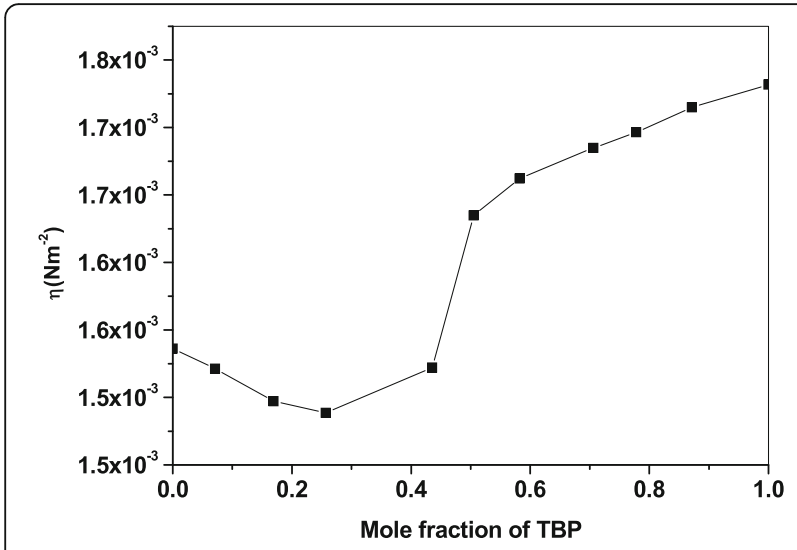

Fig. 4 Variation of viscosity with different mole fractions of TBP

The other factor is the specific interactions between unlike components such as hydrogen bond formation and charge transfer complexes which may cause increase in viscosity in mixtures over that found in pure components. The former effect produces negative deviation in excess viscosity whereas the latter effect produces positive deviation in excess viscosity. Based on this theory (Fort and Moore 1965), the observed negative values of excess viscosity may be due to smaller size of toluene as compared to that of TBP molecules (Fig. 6). However, from Fig. 7, it is observed that the excess molar volumes, $V_{m}^{E}$, is positive which can be explained by the predominance of expansion in volume, caused by the loss of dipolar association and difference in size and shape of component molecules, over contraction in volumes, due to the dipole-dipole and dipole-induced dipole interactions (Petek and Dolecek 1998). In our study, $\Delta \beta_{s}$ and $L_{f}^{E}$ negative (Figs. 8 and 9) indicates that the solvent mixture is less compressible than the pure liquids forming the complex and molecules are more tightly bound than in pure liquids. This indicates the presence of relatively stronger molecular interaction,

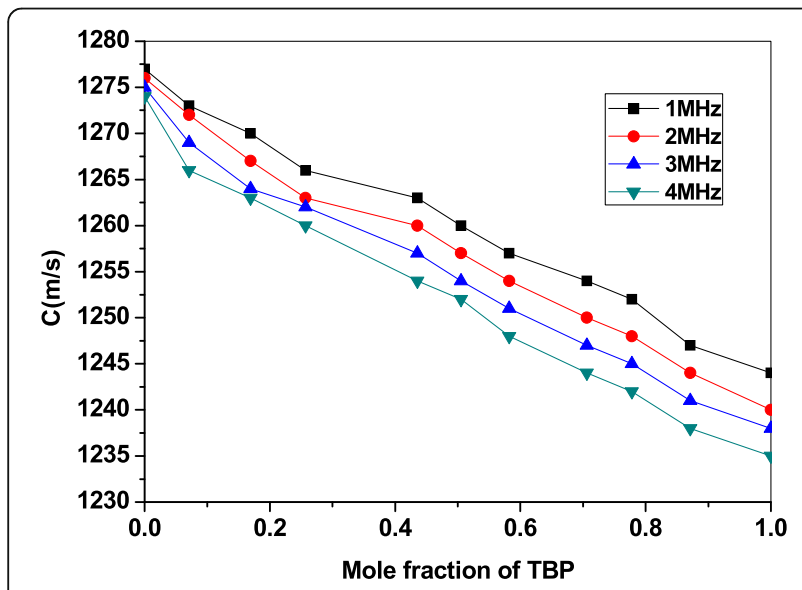

Fig. 5 Variation of ultrasonic velocity with TBP

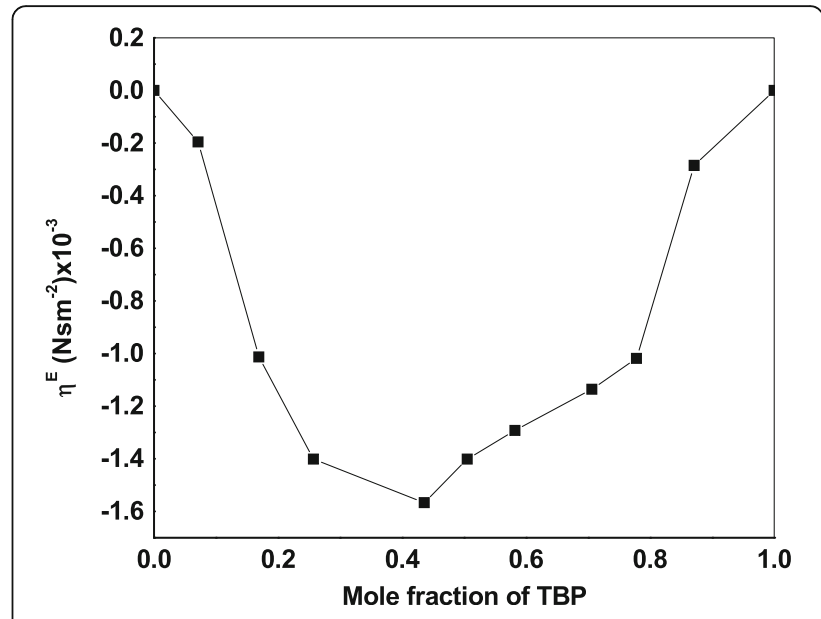

Fig. 6 Variation of excess viscosity with TBP

possible through hydrogen bonding (Ali and Nabi 2010; Nabi et al. 2013) between the component molecules. Mixing of TBP with toluene will induce the breaking up of the associated clusters of TBP releasing several dipoles which in turn can induce a dipole moment in toluene molecules, resulting dipole-induced dipole interactions. Thus, toluene acts as a structure breaker of TBP.

With the increase in frequency, the interaction becomes weak and the breaking of associated structure of TBP dominates, resulting in increase of $\Delta \beta_{s}$ (Nath and Paikaray 2009). The negative values of $L_{f}^{E}$ are attributed to close packaging of the component molecule which decreases up to $0.3 \mathrm{~mol}$ fraction of TBP and then increase negatively attributing to loose packing of the component molecules which in fact supports the heteromolecular association between the TBP and toluene. This results the decrease in free length between the component molecules indicates that the system is more resistant to the sound propagation. The positive excess acoustic impedance $\left(Z^{E}\right)$ value indicates that over the concentration range of $0.4-0.5 \mathrm{~mol} \%$ for TBP, significant

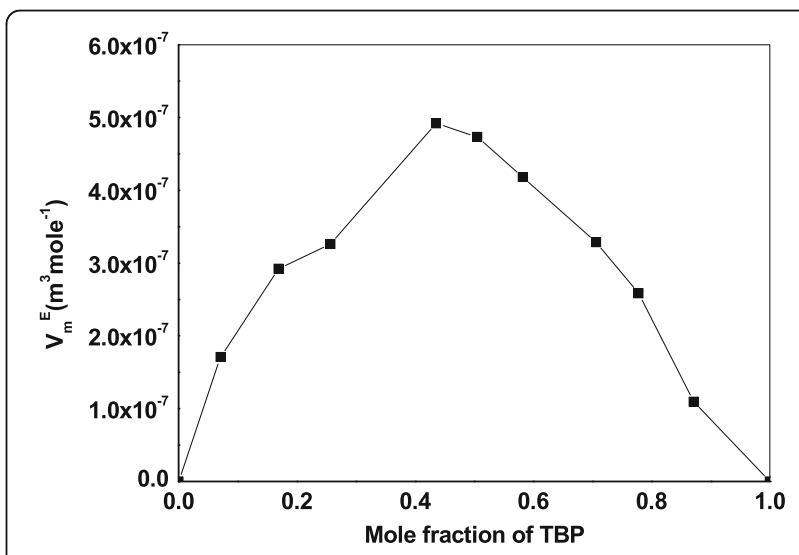

Fig. 7 Variation of excess molar volume with TBP 


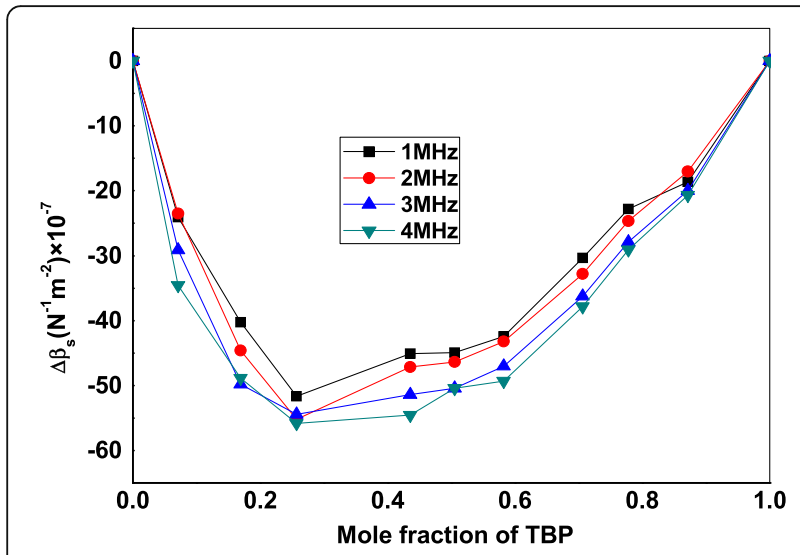

Fig. 8 Variation of deviated isentropic compressibility with TBP

interaction between the molecules of solvent is present as shown in Fig. 10. This is attributed due to interaction between component molecules and formation of closer molecular aggregates which leads to decrease in the intermolecular free space. This behavior is supposed to be caused by structural arrangement of phosphoryl group of TBP and $\mathrm{CH}_{3}$ group of toluene. Similarly, the excess surface tension is also positive throughout the system. The positive excess value indicates that the increase in molar volume indicates strong interaction between the component molecules. The maximum deviation is seen at $0.4 \mathrm{~mol}$ fraction of TBP (Fig. 11). The positive excess surface tension $\sigma^{E}$ of mixture is due to the adsorption of TBP at the interface of the toluene and TBP. The lone pair of electrons on oxygen atom of the phosphate bond is responsible for this adsorption (Schulz and Navratil 1984).

The intense discussion of physicochemical parameters of extractants and diluent makes it suitable for their compatibility up to a particular concentration $(0.4 \mathrm{~mol} \%)$ as confirms from the variation of each physicochemical parameter. Again, TBP is a polar liquid having dipole

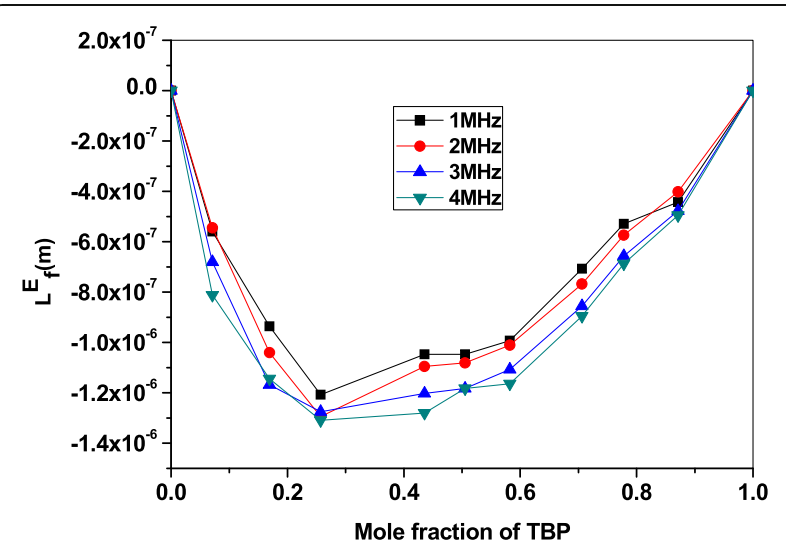

Fig. 9 Variation of excess intermolecular free length with TBP

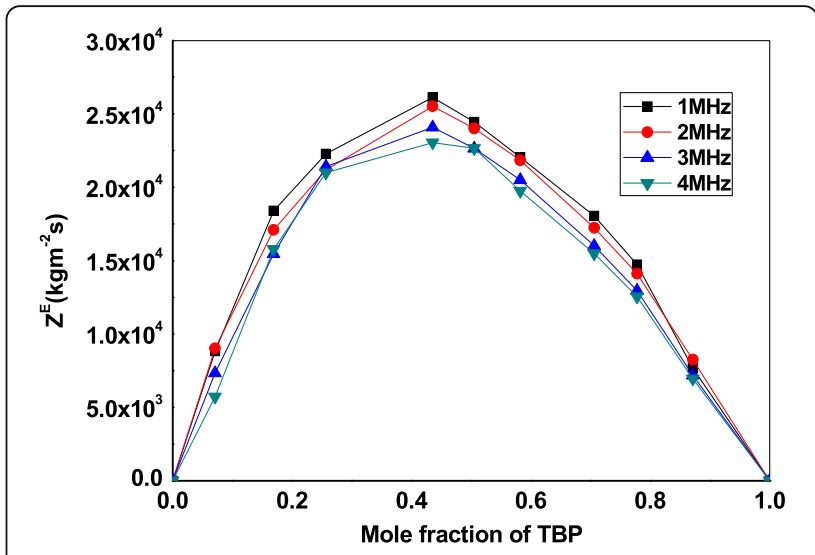

Fig. 10 Variation of excess acoustic impedance with TBP

moment $\mu=2.92 \mathrm{D}$ and dielectric constant $\varepsilon=8.29$. As TBP is known to be a mildly associated polar liquid having liner correlation factor $(g>1)$ (Bottcher 1973), it can remain in head tail arrangement with $\alpha$-multimerization. With addition of nonpolar liquid like toluene, breaking of $\alpha$-multimers takes place which facilitates the extraction processes. For the extraction process, each concentration of $\mathrm{TBP} /$ toluene was treated with $\mathrm{CeO}_{2}$ in addition of $\mathrm{HNO}_{3}$ and the distribution coefficient recorded as per Nernst distribution law and tabulated in Table 5. The extraction of cerium increased steadily with an increase in TBP concentration up to $0.4 \mathrm{~mol}$ fraction and then plateaued as shown in Fig. 12. Though diluent is unable to extract metal ion from the aqueous phase, they greatly affect the extraction behavior of extractant (Habashi 1993).

\section{Conclusions}

The ultrasonic study of TBP and toluene is a nondestructive investigation used for probing the nature of the acoustical and molecular interaction in solvent mixture. The acoustic data of ultrasonic velocity,

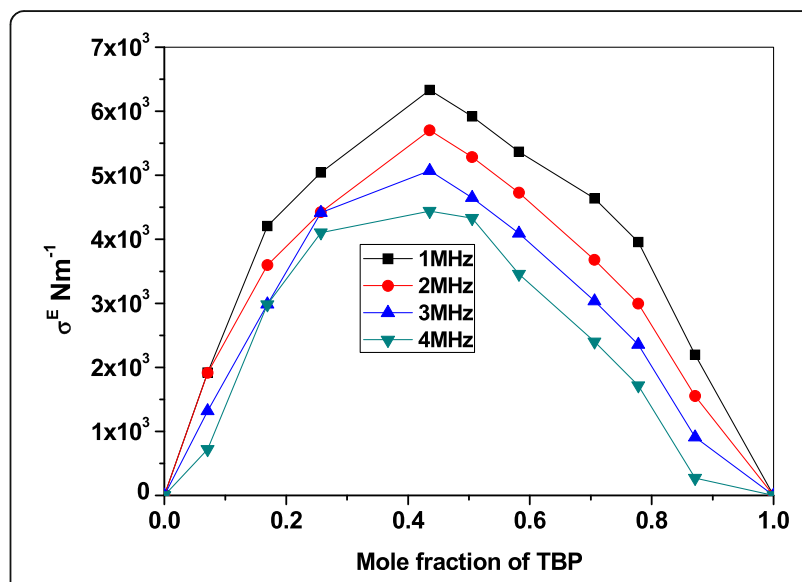

Fig. 11 Variation of excess surface tension for different mole fractions of TBP 


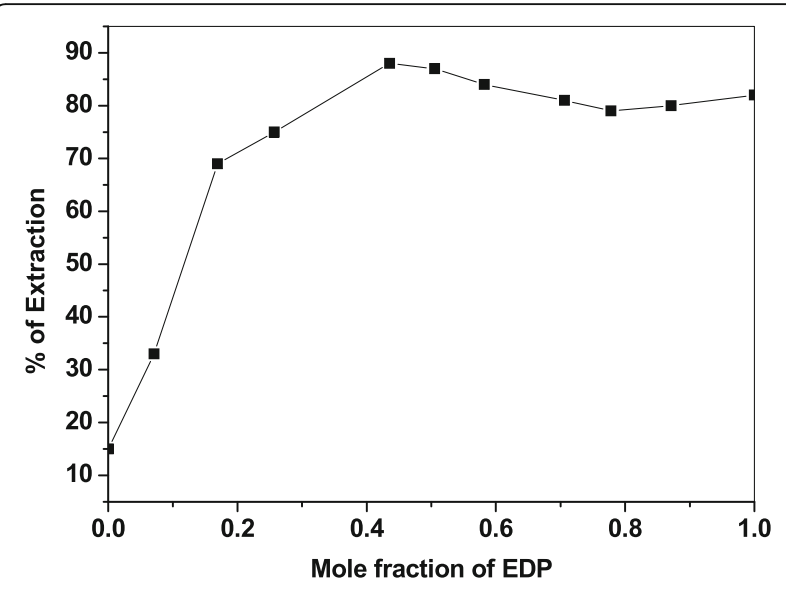

Fig. 12 Percent of extraction for different mole fractions of EDP

density, viscosity, molar volume, and acoustic parameters with their excess values of TBP with toluene over the different concentration range suggest the existence of a strong molecular interaction like dipoleinduced dipole, dipole-dipole, and hydrogen bonding type. The frequency of the ultrasonic wave also influences the intermolecular interaction as all the parameters are based on the computation of ultrasonic velocity. The change of deviated and excess physicochemical parameter from certain concentration hints the presence of compatibility of the solvent mixture. Again, the extraction of cerium for each concentration of TBP and toluene indicates the maximum efficiency of the TBP and toluene is the same as demonstrated by each physicochemical parameter. The nature of interaction present in the TBP and toluene mixture provides an optimized value for the extraction process. As such, toluene with TBP may be used as effective diluents/modifiers in the extraction of cerium from cerium oxide material.

\section{Acknowledgements}

The authors are thankful to Hon'ble Vice chancellor and Dean (PGS \& R) for providing the financial support and laboratory facilities to carry out the research work.

\section{Authors' contributions}

RG carried out preparation of sample for the experimental work, measured and computed different experimental datas under the guidance of GN also participate in the sequene alignment, scientific analysis and discussion of the different results. All authors read and approved the final manuscript.

\section{Competing interests}

The author declare that they have no competing interests.

Received: 22 March 2016 Accepted: 21 September 2016

Published online: 29 September 2016

\section{References}

Ali A, Nabi F. J Disp Sci Tech. 2010:31:1326.

Ali A, Nain AK. Acoust Lett. 1996;19:181.

Ali A, Nain AK, Kamil M. Thermochim Acta, 1996:274:209.

Ali A, Abida, Hyder S. Phys Chem Liq. 2004;42:411.
Aswar AS, Chudhary DS. J Pure Appl Ultrason. 2014;36:46-50. Bhatanagar D, Joshi D, Kumar A, Jain CL. Ind J Pure Appl Phys. 2010:48:31. Bottcher CJF. Theory of electric polarization. Msterdam: Elsevier; 1973. p. 1. Dey R, Raghuvanshi KS, Saini A, Harshavardhan A. Int J Sci Res. 2015;251-257. http://www.ijsr.net/conf/ISU-2015/ISU-055.pdf. Fort RJ, Moore WR. Trans Faraday Soc. 1965;61:2102.

Gangwar MK, Saxena AK, Agarwal R. Adv Appl Sci Res. 2013;4(2):29.

Giri R, Nath G. J Pure Appl Ultrason. 2015;37:44-7.

Goldman S, Care GCB. Can J Chem. 1971;49:1716.

Habashi F. A text book of hydrometallurgy. Metallurgie extractive Quebec, Enr. 1993. Joshi D, Kumar A, Ponia TP, Kumar B, Bhatanagar D. J Pure Appl Ultrason. 2010;

$$
\text { 32:22-31. }
$$

Laxmi BJ, Satyanarayana GR, GouriSankar M, Ramachandran D, Rambabu C. Chem Sci Trans. 2015;4(1):17.

Liu C, Cao J, Shen W, Ren Y, Mu W, Ding X. Fluid Phase Equilib. 2016:408:190. Mahapatra PK, Rout DR, Sengupta R. Sep Purif Technol. 2014;133:69. Matsumiya M, Kikuchi Y, Yamada T, Kawakami S. Sep Purif Technol. 2014;130:91. Moumouzias G, Ritzoulis G. J Chem Eng Data. 1992;37(4):482.

Nabi F, Jesudason CG, Malik MA, Al-Thabaiti SA. Chem Eng Commun. 2013;200:77. Nadh ML, Mohan TM, Krishna TV, Kumar CRS. Ind J Pure Appl Phys. 2013;51:406. Nath G, Paikaray R. Ind J Phys. 2009;9:763.

Nath G, Sahu S, Paikaray R. Ind J Phys. 2009a:4:429.

Nath G, Sahu S, Paikaray R. Ind J Phys. 2009b;11:1567.

Pal A, Kumar B. J Mol Liq. 2011;163:128.

Palani R, Kalavathy S. J Pure Appl Ultrason. 2011;33:21-5.

Patel JP, Parsania PH. J Pure Appl Ultrason. 2010:32:84-7.

Petek A, Dolecek V. Acta Chim Slov. 1998;45:153.

Pradhan SK, Das SK, Moharana L, Swain BB. Ind J Pure Appl Phys. 2012;50:161.

Sakthipandi K, Rajendran V, Jayakumar T. J Pure Appl Ultrason. 2012;34:69-71.

Schulz WW, Navratil JD. Science and technology of tributyl phosphate, CRC press. 1984. Shieh PS, Fendler JH. J Chem Soc Farad. 1977;173:1480.

Srivastava R, Pandey A, Gupta RK, Gupta A. J Pure Appl Ultrason. 2014;36:36-45.

Thirumaran S, Jayakumar JE. Ind J Pure Appl Phys. 2009;47:265.

Tuck DG. Trans Faraday Soc. 1961;57:1297.

\section{Submit your manuscript to a SpringerOpen ${ }^{\odot}$ journal and benefit from:}

- Convenient online submission

- Rigorous peer review

- Immediate publication on acceptance

- Open access: articles freely available online

- High visibility within the field

- Retaining the copyright to your article

Submit your next manuscript at springeropen.com 